\title{
Norcantharidin inhibits DNA replication and induces mitotic catastrophe by degrading initiation protein $\mathrm{Cdc6}$
}

\author{
SANSAN CHEN ${ }^{1,2}$, PEI WAN $^{1,2}$, WEN DING $^{1}$, FEI LI $^{2}$, CHENGWU HE $^{1,2}$, PENGLIANG CHEN $^{2}$, \\ HONGWEI LI ${ }^{1}$, ZHIMING HU ${ }^{1}$, WANLONG TAN ${ }^{2}$ and JINLONG LI ${ }^{1}$ \\ ${ }^{1}$ Institute of Biotherapy, School of Biotechnology, ${ }^{2}$ Department of Urology, Nanfang Hospital, \\ Southern Medical University, Guangzhou, Guangdong 510515, P.R. China
}

Received February 11, 2013; Accepted April 8, 2013

DOI: $10.3892 /$ ijmm.2013.1359

\begin{abstract}
Cdc6, an essential initiation protein for DNA replication, also participates in the ATR checkpoint pathway and plays a vital role in tumorigenesis. It is involved in the androgen receptor (AR) signal transduction and promotes the malignant progression of prostate cancer ( $\mathrm{PCa}$ ). In this study, we report that norcantharidin (NCTD) induces the degradation of Cdc6 in DU145 PCa cells and as a result, the assembly of pre-replication complexes (pre-RCs) was disturbed and DNA replication was inhibited. Furthermore, treatment with NCTD blocked ATR binding to chromatin and the cells progressed into mitosis under stress induced by hydroxyurea (HU), indicating that the ATR checkpoint was evaded. Aberrant mitosis and hence, apoptosis were also observed following treatment with NCTD. Finally, NCTD exerted strong synergistic cytotoxic effects in combination with another mitotic inhibitor, paclitaxel, [combination index $(\mathrm{CI}<1)]$. These data suggest that NCTD not only inhibits DNA replication but also disables the ATR-dependent checkpoint pathway by inducing Cdc6 degradation, which leads to mitotic catastrophe in DU145 cells. These findings also provide a promising prospect for the combination treatment of paclitaxel and NCTD or Cdc6 deletion in PCa.
\end{abstract}

\section{Introduction}

Prostate cancer ( $\mathrm{PCa})$ is one of the most commonly diagnosed types of cancer in the older male population (1). It accounts for 15 and $4 \%$ of male cancer cases in developed and developing countries, respectively (2). The androgen receptor (AR) plays a

Correspondence to: Professor Wanlong Tan, Department of Urology, Nanfang Hospital, Southern Medical University, 1838 Guangzhou Dadao Bei, Guangzhou, Guangdong 510515, P.R. China

E-mail: tanwanlong@gmail.com

Professor Jinlong Li, Institute of Biotherapy, School of Biotechnology, Southern Medical University, 1838 Guangzhou Dadao Bei, Guangzhou, Guangdong 510515, P.R. China

E-mail: lijinlong75@126.com

Key words: norcantharidin, Cdc6, DNA replication, ATR, mitotic catastrophe pivotal role in the onset and malignant progression of $\mathrm{PCa}$ (3). It has been reported that $\mathrm{Cdc} 6$, a replication licensing protein, is involved in AR signal transduction and plays a role in the malignant progression of PCa. AR targets the human Cdc6 gene for transcriptional regulation and Cdc6 is also modulated at the transcription level by androgen or anti-androgen treatment in androgen-sensitive PCa cells (4,5). AR binds at a distinct androgen-response element (ARE) in the Cdc6 promoter that is functionally required for androgen-dependent Cdc6 transcription (6-9). AR silencing in PCa cells has been shown to markedly decrease Cdc6 expression and androgen-dependent cellular proliferation (10).

In all eukaryotes, there are several initiation sites of DNA replication, and each DNA segment replicates only once during each cell cycle (11). Prior to DNA replication, pre-replication complexes (pre-RCs) must be assembled at the replication sites in cells in the G1 phase (12). Cdc6 plays a crucial role in the assembly of pre-RCs by linking origin recognition complex (Orc) with minichromosome maintenance $(\mathrm{Mcm})$ proteins to form pre-RCs at the sites of DNA replication (13). During the early G1 phase, Cdc6 is firstly recruited to bind to Orc, which is a indispensable step for the subsequent loading of $\mathrm{Mcms}$ onto the chromatin (14). Cdc6 is also involved in regulating the progression of the cell cycle at the $\mathrm{G} 2 / \mathrm{M}$ phase by interacting with ATR (15). If Cdc6 is inhibited, the ATR-dependent checkpoint pathway cannot be activated in the case of DNA replication stress (15), which may lead to aberrant mitosis, a condition that is lethal to cancer cells as a consequence of the lack of supervision of mitotic entry. Therefore, Cdc6 may be a potential anticancer target.

Cantharidin is the main ingredient for the anticarcinogenic effect of Mylabris, which has been used for antitumor treatment in Traditional Chinese Medicine for centuries. However, its nephrotoxic and phlogogenic side-effects limit its clinical application (16). Norcantharidin (NCTD), a demethylated analog of cantharidin, has been shown to exert a strong antitumor effect on many types of cancer, such as primary hepatic carcinoma (17), lung (18), colorectal (19), breast (20) and oral cancer (21). Unlike the majority of anticancer drugs, the significant advantages of NCTD are that it induces little myelosuppression and induces leucocytosis (22). In this study, we report that NCTD inhibits androgen-insensitive $\mathrm{PCa}$ cell growth, induces mitotic catastrophe and enhances 
the anticancer effects of paclitaxel in vitro. As shown by our results, NCTD degraded Cdc6 and Mcm6 in DU145 cells, and disturbed the chromatin binding of Cdc6, Mcm2 and Mcm6. Although DNA synthesis was inhibited by NCTD, the ATR, which participates in the checkpoint pathway in the case of replication stress, was inhibited. As a result, aberrant mitosis was observed. In addition, combination treatment with NCTD and paclitaxel displayed strong synergistic anticancer effects.

\section{Materials and methods}

Materials. Dulbecco's modified Eagle's medium (DMEM) was purchased from Gibco/Life Technologies (Carlsbad, CA, USA). Fetal bovine serum (FBS), penicillin, streptomycin, and all other tissue culture reagents were obtained from Thermo Scientific HyClone (Logan, UT, USA). Paclitaxel and propidium iodide (PI) were purchased from Sigma Chemical Co. (St. Louis, MO, USA).

Cell culture and synchronization. DU145 cells were cultured in DMEM with $10 \%$ FBS (v/v) and penicillin (100 U/ml)/ streptomycin $(100 \mu \mathrm{g} / \mathrm{ml})$. Cultures were maintained in a humidified incubator at $37^{\circ} \mathrm{C}$ in a $5 \% \mathrm{CO}_{2}$ incubator. When the cells reached $30 \%$ confluence, they were synchronized at the late G1 phase if necessary by the addition of mimosine $(0.5 \mathrm{mM})$ for $20 \mathrm{~h}$ and then released into fresh medium.

Cell proliferation assay. 3-(4,5-dimethylthiazol-2-yl)-2,5-diphenyltetrazolium bromide (MTT; Sigma) tests were performed to evaluate the cytotoxic effects in vitro. Briefly, DU145 cells were plated in 96 -well plates $\left(8 \times 10^{3}\right.$ cells/well). Following treatment with NCTD for $48 \mathrm{~h}$ at the indicated concentrations, MTT was added to each well (100 $\mu \mathrm{g} /$ well) followed by incubation for an additional $4 \mathrm{~h}$. The produced insoluble formazan was dissolved with $200 \mu \mathrm{l}$ DMSO and the optical density (OD) was measured using an ELISA reader (Thermo Labsystems, Helsinki, Finland) at wavelengths of 570 and $630 \mathrm{~nm}$. The experiments were carried out in triplicate.

BrdU incorporation assay. The DU145 cells were seeded onto 22-mm diameter coverglasses placed in 6-well plates ( $3 \times 10^{5}$ cells/coverglass). One hour prior to fixing the cells, $10 \mu \mathrm{M}$ BrdU (Sigma Chemicals) were added to the cultures. The cells were rinsed and fixed in $4 \%$ phosphate-buffered paraformaldehyde for $10 \mathrm{~min}$. Following aspiration, the cells were rinsed 3 times in PBS for $5 \mathrm{~min}$ and $0.2 \%$ Triton X-100 was added to the specimens for $10 \mathrm{~min}$. The specimens were then incubated in $4 \mathrm{M} \mathrm{HCl}$ after being rinsed 3 times in PBS for $5 \mathrm{~min}$. After neutralization using PBS, the specimens were blocked in goat serum for $60 \mathrm{~min}$. The blocking solution was aspirated and the specimens were incubated in diluted primary mouse-monoclonal antibody to BrdU (1:1,000, Cell Signaling Technology Inc., Beverly, MA, USA) overnight at $4^{\circ} \mathrm{C}$. After rinsing 3 times in PBS for $5 \mathrm{~min}$, the specimens were incubated in fluorochrome-conjugated secondary antibody diluted in PBS at room temperature in the dark and observed under fluorescent microscope. At least 1,000 cells/treatment using at least 2 coverglasses/treatment were counted, and the number of positive cells was recorded. Labeling indexes were calculated as the number of positively stained cells divided by the number of total cells.
Western blot analysis. The cells were harvested and suspended in ice-cold lysis buffer (50 mM Tris- $\mathrm{HCl} \mathrm{pH}$ 7.5, $150 \mathrm{mM}$ $\mathrm{NaCl}, 1 \% \mathrm{NP}-40,1 \mathrm{mM} \mathrm{PMSF}$ and $10 \mathrm{U} / \mathrm{ml}$ aprotinin) for $20 \mathrm{~min}$, then centrifuged at $12,000 \mathrm{rpm}$ for $10 \mathrm{~min}$ at $4^{\circ} \mathrm{C}$. Total proteins were separated by $10 \%$ SDS-PAGE and transferred onto polyvinylidene fluoride membranes. The membranes were blocked with TBS containing $0.1 \%$ Triton X-100 and 5\% non-fat milk for $1 \mathrm{~h}$ at room temperature, then incubated with rabbit-anti-human monoclonal antibody against Cdc6 (1:1,000; Cell Signaling Technology Inc., Danvers, MA, USA), rabbitanti-human monoclonal against Mcm2 (1:1,000, Cell Signaling Technology), goat polyclonal antibody against Mcm3 (1:500, Santa Cruz Biotechnology, Inc., Santa Cruz, CA, USA), mouseanti-human monoclonal antibody against Mcm6 (1:500, Santa Cruz Biotechnology, Inc.) and rabbit-anti-human monoclonal against GAPDH (1:2,000, Cell Signaling Technology) at $4^{\circ} \mathrm{C}$ overnight. After washing, the membranes were incubated with HRP-conjugated Ig at room temperature for $1 \mathrm{~h}$. Signal detection was carried out with an ECL system (Millipore, Billerica, MA, USA).

Chromatin binding assay. The cells were harvested and resuspended in tubes with extraction buffer $(100 \mathrm{mM} \mathrm{KCl}$, $50 \mathrm{mM}$ HEPES-KOH pH 7.5, $2.5 \mathrm{mM} \mathrm{MgCl}_{2}, 50 \mathrm{mM} \mathrm{Na}_{4} \mathrm{P}_{2} \mathrm{O}_{7}$, $0.1 \mathrm{mM} \mathrm{NaVO}, 0.5 \%$ Triton X-100) containing protease inhibitors, then set on ice for 5 to $10 \mathrm{~min}$ for incubation. The tubes were flicked to mix the solution every 2-3 min during incubation. Subsequently, $30 \%$ ice-cold sucrose containing protease inhibitors was added to the bottom of the tubes. The tubes were then spinned in a microfuge, $12-15 \mathrm{krpm}, 10 \mathrm{~min}, 4^{\circ} \mathrm{C}$ and the supernatants were transferred to new tubes. The pellets were washed with EB buffer and flicked to dislodge the pellets from the wall of the tubes and vortexed briefly for resuspension, followed by spinning in a microfuge, $12-15 \mathrm{krpm}, 5 \mathrm{~min}, 4^{\circ} \mathrm{C}$. The supernatants were saved and combined (this is the nonchromosomal fraction) from this and the previous step. The pellets were resuspended with EB buffer (the pellets are the chromatin-binding fraction). The supernatants and the pellets were then used for western blot analysis.

Nuclear staining. For nuclear staining, the cells were treated with or without 50 or $100 \mu \mathrm{M}$ NCTD for $48 \mathrm{~h}$, washed twice with cold PBS, and fixed with $4 \%$ paraformaldehyde for $15 \mathrm{~min}$. The fixed cells were permeabilized with $0.2 \%$ Triton X-100 and then incubated with 4, 6-diamidino-2-phenylindole (DAPI) at the concentration of $5 \mu \mathrm{g} / \mathrm{ml}$ for $5 \mathrm{~min}$. A fluorescent microscope was used for imaging. At least 1,000 cells/treatment were counted, and the number of cells with signs of mitotic catastrophe was recorded. Labeling indexes were calculated as the number of cells with signs of mitotic catastrophe divided by the number of total cells.

Flow cytometric assay. Following treatment with or without hydroxyurea (HU) or NCTD/HU for $24 \mathrm{~h}$, the cells in each group were collected by Trypsin digestion. The cells were fixed with $70 \%$ alcohol and then centrifuged again for $10 \mathrm{~min}$ at $8,000 \mathrm{rpm}$. The supernatant was discarded and $500 \mu \mathrm{l} \mathrm{PI}$ staining solution $(5 \mu \mathrm{g} / \mathrm{ml}$ RNase, $0.1 \%$ Triton X-100, $0.1 \mathrm{mM}$ EDTA, $50 \mu \mathrm{g} / \mathrm{ml} \mathrm{PI}$ ) was added. The cells were then incubated away from light for $30 \mathrm{~min}$ at $4^{\circ} \mathrm{C}$. The cell cycle and apoptosis 
Table I. $\mathrm{ED}_{50}$ and concentration range for NCTD and paclitaxel.

\begin{tabular}{llc}
\hline Drug & $\mathrm{ED}_{50}$ & Concentration range \\
\hline Paclitaxel $(\mathrm{nM})$ & $772.5 \pm 316.8$ & $6.25-400$ \\
$\operatorname{NCTD}(\mu \mathrm{M})$ & $206.6 \pm 12.0$ & $6.25-400$ \\
\hline
\end{tabular}

The $\mathrm{ED}_{50}$ values of NCTD, paclitaxel and their combination were determined by MTT assay. Concentration range in MTT is indicated. Each experiment was independently carried out 3 times. Data represent the means $\pm \mathrm{SD} . \mathrm{ED}_{50}$, median effective dose for $50 \%$ of the cell population. NCTD, norcantharidin.

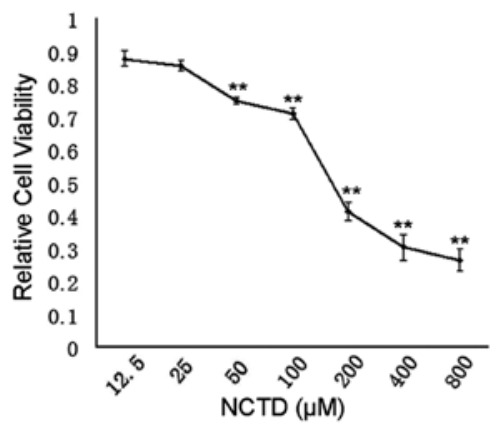

Figure 1. Norcantharidin (NCTD) inhibits DU145 cell proliferation in a dose-dependent manner. DU145 cells were treated with the indicated concentrations of NCTD for $48 \mathrm{~h}$. Cell viability was examined by MTT assay. Data from 3 separate experiments are expressed as the means $\pm \mathrm{SD}$. ${ }^{* *} \mathrm{P}<0.01$.

were then measured by flow cytometry (Becton-Dickinson, San Jose, CA, USA).

In vitro combination treatment of DU145 cells with NCTD and paclitaxel. DU145 cells were treated with NCTD in combination with paclitaxel at various concentrations for $48 \mathrm{~h}$. MTT assays were performed to detect the cell viability in vitro. Briefly, the cells were seeded on 96-well plates in 10\% FBS-containing medium at a density of 4,000 cells/well and incubated at $37^{\circ} \mathrm{C}$ for $24 \mathrm{~h}$ prior to exposure to the drugs. The cells were then treated with NCTD, paclitaxel, or a combination of both for $48 \mathrm{~h}$ at the indicated concentrations. The combination ratio of $\operatorname{NCTD}(\mu \mathrm{M})$ and paclitaxel $(\mathrm{nM})$ was 1:1 and the concentration range is presented in Table I. Cell viability was determined following treatment with the drugs for $48 \mathrm{~h}$ by MTT assay. Each experiment was performed in quintuplicate wells for each drug concentration and independently carried out 3 times. By combining both agents at graded concentrations, the combined effects of growth inhibition were obtained and analyzed using Calcusyn1 software. The combination index (CI) was calculated as follows: $\mathrm{CI}=(\mathrm{D}) 1 /(\mathrm{Dx}) 1+(\mathrm{D}) 2 /(\mathrm{Dx}) 2+(\mathrm{D}) 1(\mathrm{D}) 2 /$ (Dx)1(Dx)2; where (Dx)1 is the dose of drug 1 required to produce an $\mathrm{X} \%$ effect alone, (D) 1 is the dose of drug 1 required to produce the same $\mathrm{X} \%$ effect in combination with drug 2, (Dx) 2 is the dose of drug 2 required to produce an X\% effect alone, and (D) 2 is the dose of drug 2 required to produce the same $\mathrm{X} \%$ effect in combination with drug 1 .

The effects of the combination treatment were then transformed and displayed as FA-CI plots. The combined effects

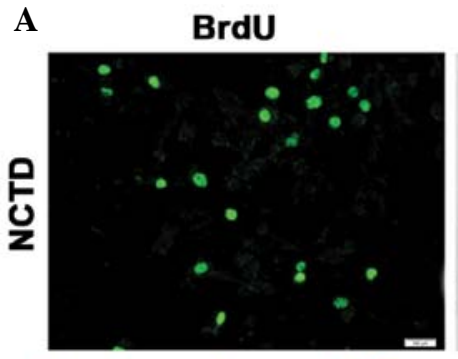

Bright field

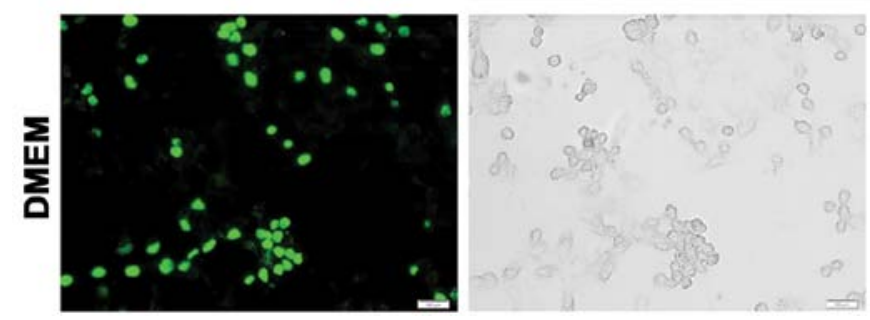

B

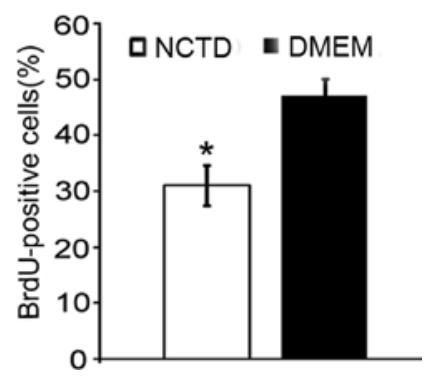

Figure 2. Norcantharidin (NCTD) inhibits DNA synthesis in DU145 cells DU145 cells were treated with or without $100 \mu \mathrm{M}$ NCTD for $24 \mathrm{~h}$. (A) Cells were incubated with BrdU for $1 \mathrm{~h}$ following treatment with NCTD for $24 \mathrm{~h}$. The BrdU-positive cells were then identified by immunofluorescence staining and observed under a fluorescence microscope. (B) The proportion of BrdU-positive cells. Data are expressed as the means of the percentage of BrdU-positive cells \pm SD. ${ }^{*} \mathrm{P}<0.05$, as compared to Dulbecco's modified Eagle's medium (DMEM) control.

were determined as follows: $\mathrm{CI}<1$, synergy; $\mathrm{CI}=1$, zero interaction (strictly additive effects); and CI $>1$, antagonism.

Statistical analysis. Average values are expressed as the means \pm standard deviation (SD). Statistical significance between different groups was determined using the Student's t-test. A P-value $<0.05$ was considered to indicate a statistically significant difference.

\section{Results}

Effect of NCTD on tumor cell proliferation. To evaluate the effects of NCTD inhibition on the proliferation of DU145 PCa cells, MTT assay was carried out. In the NCTD-treated group, a dose-dependent suppression of cell proliferation was observed. NCTD effectively inhibited the proliferation of DU145 cells, with an $\mathrm{IC}_{50}$ of $\sim 200 \mu \mathrm{M}$ (Fig. 1).

BrdU incorporation assay. We investigated whether NCTD inhibits the proliferation of DU145 cells by suppressing DNA synthesis. The BrdU incorporation assays revealed that $\sim 47 \%$ of the PCa cells in the control group were able to incorporate $\mathrm{BrdU}$, while in the NCTD-treated group, the number of BrdU-positive cells decreased to $31 \%$ (Fig. 2A and B). NCTD significantly inhibited DNA replication $(\mathrm{P}<0.05)$. 
A

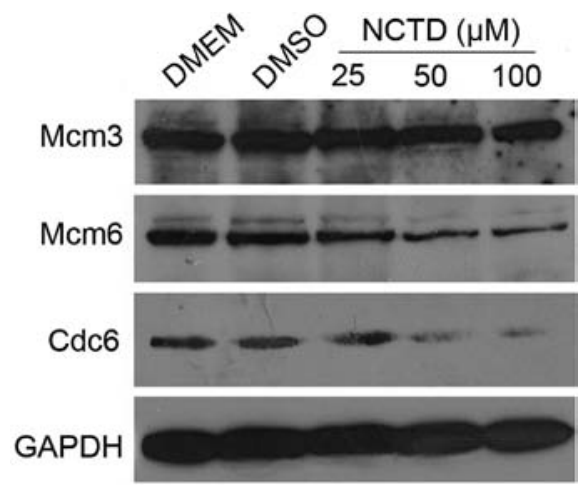

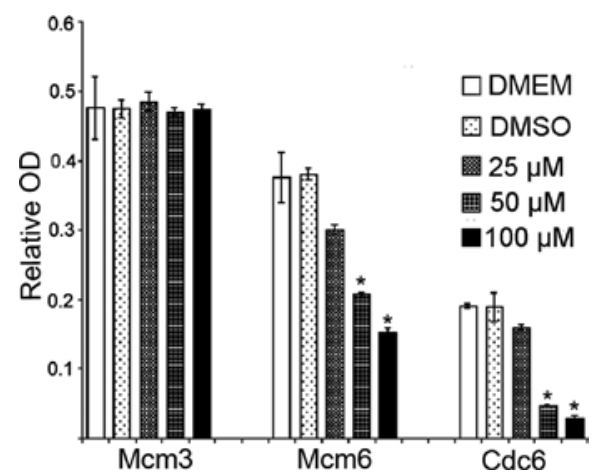

Figure 3. Norcantharidin (NCTD) induces degradation of initiation proteins in DU145 cells. DU145 cells were treated with the indicated concentrations of NCTD for $48 \mathrm{~h}$. Total proteins following treatment with NCTD were collected. (A) Cdc6, Mcm3 and Mcm2 proteins were analyzed by western blot analysis. GAPDH was used as the loading control. (B) Data are expressed as optical density (OD) fold difference related to GAPDH (relative OD) in 3 duplicate experiments. ${ }^{*} \mathrm{P}<0.05$.

$\mathbf{A}$

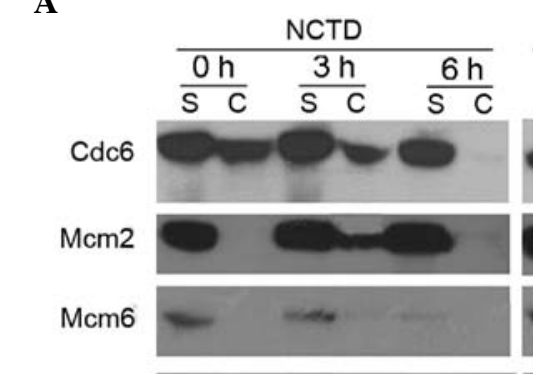

Ponceau S

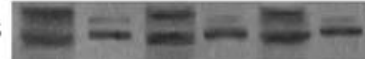

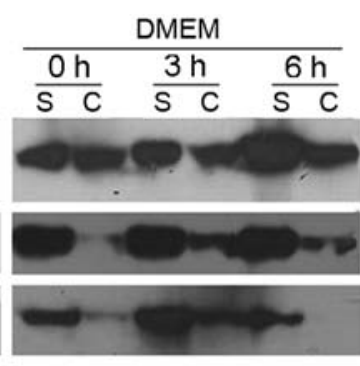

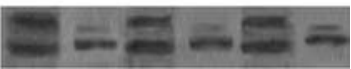

C

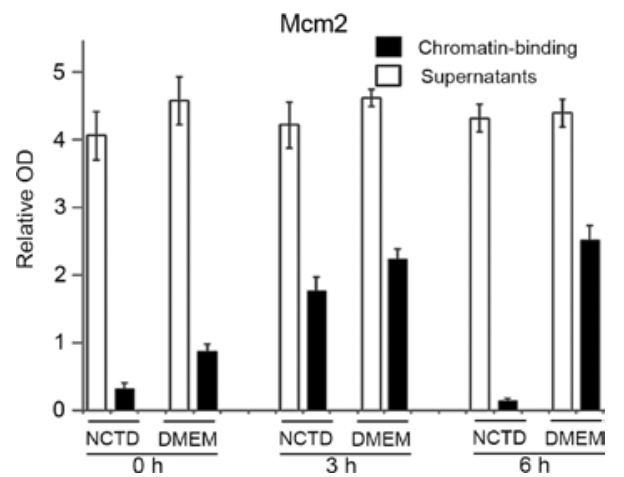

B

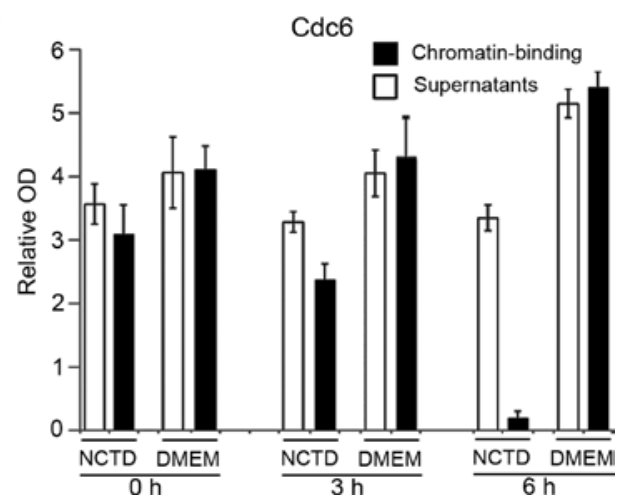

D

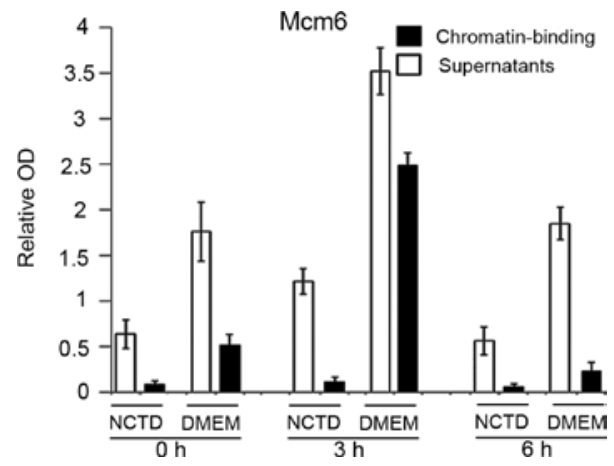

Figure 4. Norcantharidin (NCTD) disturbs the assembly of the pre-replication complexe (pre-RC) in G1 phase synchronized DU145 cells. DU145 cells were incubated with mimosine $(0.5 \mathrm{mM})$ for $20 \mathrm{~h}$. NCTD $(100 \mu \mathrm{M})$ was added $8 \mathrm{~h}$ prior to the release of mimosine. Cells were collected at 0,3 , and $6 \mathrm{~h}$ after the release of mimosine. Ponceau S staining was used as the loading control. (A) The chromatin binding of Cdc6, Mcm2 and Mcm6 was detected by chromatin binding assay. S, supernatant; C, chromatin-binding. (B-D) Data are expressed as optical density (OD) fold difference related to GAPDH (relative OD), (B) for Cdc6, (C) for $\mathrm{Mcm} 2$ and (D) for Mcm6. Assays were performed in triplicate.

NCTD induces the degradation of pre-RC proteins. To further characterize the inhibitory effect of NCTD on DNA replication, we examined the effects of NCTD on pre-RC proteins. Total proteins from NCTD-treated DU145 cells were analyzed by western blot analysis. Of the pre-RC components, Cdc6, $\mathrm{Mcm} 3$ and Mcm6 are the most frequently reported proteins that are overexpressed in tumors. Our results revealed that Cdc6 and Mcm6 were significantly degraded in a dose-dependent manner following treatment with NCTD, as compared with the control group (Fig. 3A and B).

NCTD disturbs the assembly of pre-RC in G1 cells. In G1 phase cells, Cdc6 resides in the nucleus and is essential for pre-RC formation and replication initiation (23). The end result of pre-RC formation is the loading of $\mathrm{Mcms}$ onto origin DNA (24). To examine the inhibitory effect of NCTD on the assembly of pre-RC, the cells were incubated with mimosine for $20 \mathrm{~h}$ and then released into fresh medium with or without NCTD (NCTD was added $8 \mathrm{~h}$ prior to the release of mimosine). The cells were collected at 0,3 and $6 \mathrm{~h}$ after the release of mimosine. The chromatin binding of $\mathrm{Cdc} 6, \mathrm{Mcm} 2$ and $\mathrm{Mcm} 6$ was examined by chromatin-binding assay. Our results indicated that NCTD significantly reduced the chromatin binding of Cdc 6 and Mcm 2 in the cells at the $6 \mathrm{~h}$ time point (Fig. 4A-C). The chromatin binding of Mcm6 was significantly decreased in cells at all time points (Fig. 4A and D). The results revealed that 
A

\section{$\frac{\text { Control }}{S \quad C} \quad \frac{50 \mu M}{S C} \quad \frac{100 \mu M}{S C} \quad \frac{200 \mu M}{S C}$}

ATR $S \mathrm{C}$

Cdc6

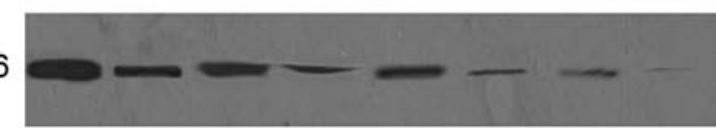

Ponceau S

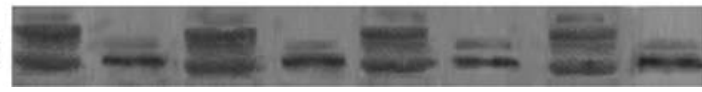

B

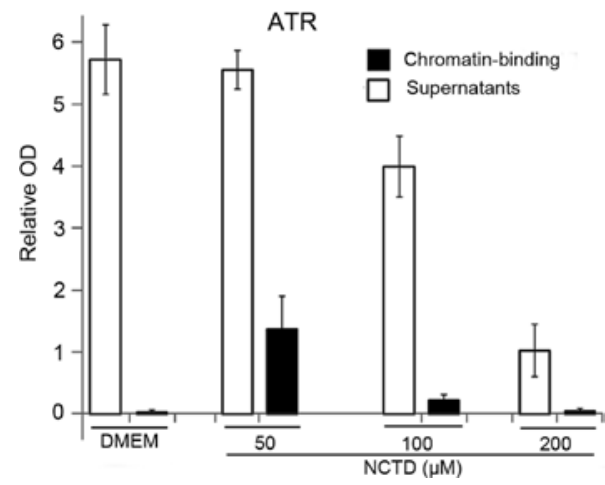

C

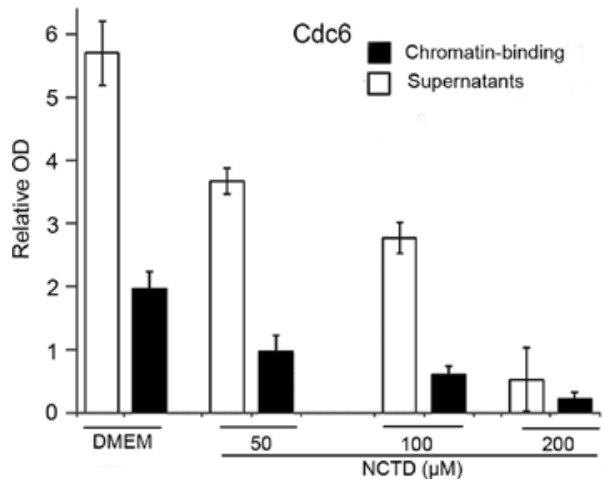

Figure 5. Norcantharidin (NCTD) disturbs the chromatin binding of ATR and Cdc6 in DU145 cells. Cells were cultured in medium containing the indicated concentrations of NCTD for $48 \mathrm{~h}$. (A) Chromatin binding assays were performed to analyze the amount of ATR and Cdc6 in chromatin-binding and non-chromosomal fractions. S, supernatant; C, chromatin-binding. (B and C) The protein levels of ATR and Cdc6 in chromatin-binding or non-choromatinbinding fractions are expressed as optical density (OD) fold difference related to GAPDH (relative OD). Ponceau S staining was used as the loading control.

NCTD disturbed the assembly of Cdc6, Mcm2 and Mcm6 onto chromatin.

NCTD disturbs ATR binding to chromatin and disables the $S$ - $M$ checkpoint. Previous studies have shown that Cdc6 is not only required for G1 origin licensing, but is also crucial for proper $S$ phase DNA replication and participates in the S-M checkpoints (25). As shown in a previous study, the loss of Cdc6 did not activate the ATR-dependent DNA damage response and induced aberrant mitosis (25). It has been reported that human Cdc6 physically interacts with ATR, in a manner that is stimulated by phosphorylation by $\mathrm{Cdk}$, and the presence of Cdc6 during the S phase is essential for ATR to bind to chromatin in response to replication inhibition (15).
In our study, NCTD effectively degraded Cdc6 in DU145 cells (Figs. 3 and 4). Thus, there is a possibility that NCTD can inhibit ATR binding to chromatin by the degradation of Cdc6. Our results revealed that few ATR chromatin-binding fractions were detected in the control group, suggesting that the ATR-dependent checkpoint pathway was not activated without DNA replication stress (Fig. 5A and B). In the lowdose NCTD-treated groups $(50 \mu \mathrm{M})$, ATR was detected in chromatin, suggesting that DNA replication was inhibited and ATR was activated. However, under higher doses of NCTD (100 and $200 \mu \mathrm{M}$ ), ATR disappeared from chromatin. In addition, the chromatin binding of Cdc6 signficantly decreased in a dose-dependent manner following treatment with NCTD (Fig. 5A and C). These results suggested that NCTD (lower dose) activates the ATR-dependent checkpoint pathway by inducing DNA replication stress. However, at the same time, NCTD (higher dose) also attenuates the ATR-dependent checkpoint activity by inhibiting ATR binding to chromatin, which may be due to the Cdc6 degradation.

ATR plays a crucial role in the S-M checkpoint pathway by signaling to Chk1 and conferring G2/M arrest when the cells are under replication stress (26). This surveillance warrants cells will not transit into mitosis before the completion of the $S$ phase $(15,27)$. To further characterize the inhibitory effect of NCTD on the S-M checkpoint, we examined the influence of NCTD on HU-induced S phase arrest. The results revealed that $\mathrm{HU}$ effectively induced S phase arrest (31\%) and the cells did not progress into the $\mathrm{G} 2 / \mathrm{M}$ phase $(0 \%)$. In the NCTD group, $26 \%$ of the cells still progressed into the $\mathrm{G} 2 / \mathrm{M}$ phase under $\mathrm{HU}$ stress. Of note, there was a significant accumulation of cells in the sub-G1 phase in the NCTD/HU-treated group, suggesting that the aberrant mitosis led to apoptosis (Fig. 6).

NCTD induces mitotic catastrophe in DU145 cells. In our experiments, DNA replication was inhibited by NCTD. Simultaneously, the chromatin binding of ATR and hence, the S-M checkpoint was also prevented. Thus, it is rational to suggest that treatment with NCTD may induce aberrant mitosis by simultaneously disturbing DNA replication and disabling the S-M checkpoint. The results from DAPI nuclear staining revealed that following treatment with NCTD, the cells underwent mitotic catastrophe, indicated by the presence of cells with micronuclei and giant multinucleated cells (28). The percentages of DU145 cells exposed to 50 or $100 \mu \mathrm{M}$ NCTD which underwent mitotic catastrophe were $\sim 11$ and $17 \%$, respectively, significantly higher than those of the control group (Fig. 7A and $\mathrm{B})(\mathrm{P}<0.05)$.

Synergism of NCTD with paclitaxel in PCa DU145 cells. As a microtubule-poisoning drug, paclitaxel can induce mitotic catastrophe and is effective for PCa therapy. As opposed to the NCTD-induced mitotic catastrophe, paclitaxel interferes with the normal breakdown of microtubules during cell division (29,30). Therefore, a combination of these 2 drugs, may produce synergistic effects. In this study, we investigated whether NCTD and paclitaxel exert synergistic effects. As shown by our results, a strong synergistic anticancer effect on DU145 cells was observed with the combination treatment of NCTD and paclitaxel at a low concentration range $(\mathrm{CI}<1)$ (Fig. 8). Our findings provide justification for the further devel- 

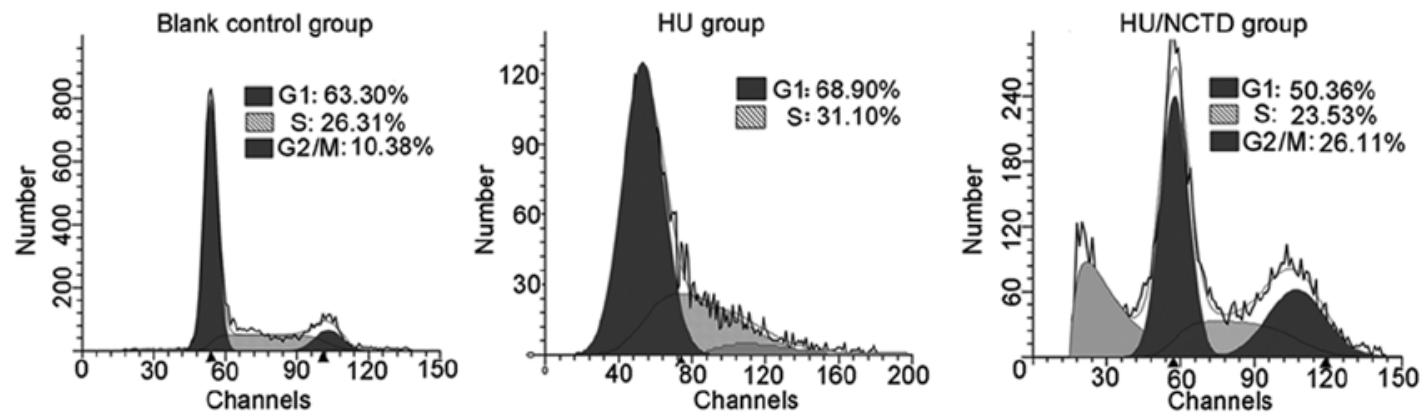

Figure 6. Norcantharidin (NCTD) abolishes hydroxyurea (HU)-induced S phase arrest. DU145 cells were treated with or without $2 \mathrm{mM} \mathrm{HU}$ or $2 \mathrm{mM} \mathrm{HU}+$ $200 \mu \mathrm{M}$ NCTD (HU/NCTD). The cell cycle of DU145 cells was determined by PI staining and detected by FCM. Assays were performed in triplicate and a representative of cell cycle distribution is presented in the figure.

A

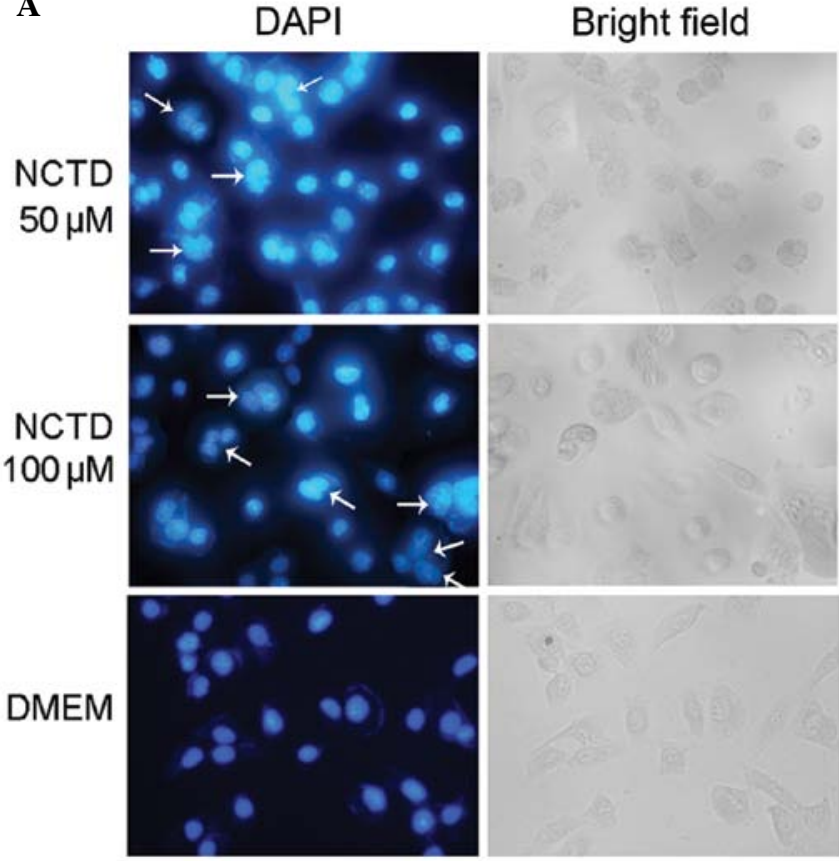

B

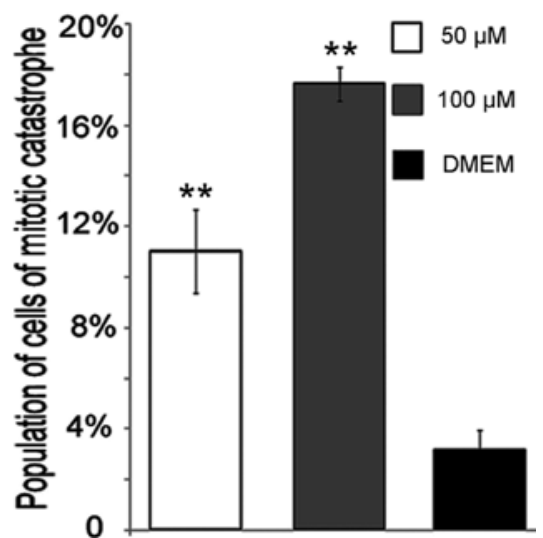

Figure 7. Norcantharidin (NCTD) induces mitotic catastrophe in DU145 cells DU145 cells were treated with the indicated concentrations of NCTD for $48 \mathrm{~h}$ (A) The nuclei were stained with DAPI and then observed under a fluorescence microscope; cells undergoing mitotic catastrophe are indicated by white arrows. (B) Data are expressed as the mean percentages of cells undergoing aberrant mitosis \pm SD. ${ }^{* *} \mathrm{P}<0.01$.

opment of the combined treatment with NCTD and paclitaxel for the treatment of PCa.

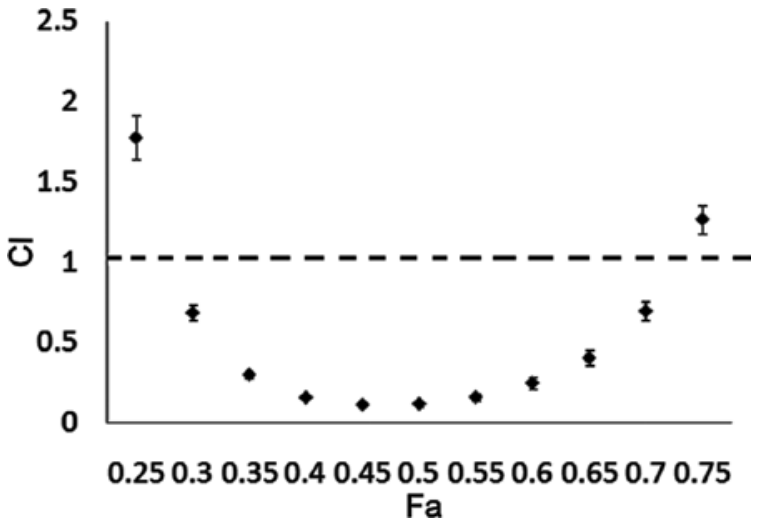

Figure 8. Synergistic cytotoxic effect of norcantharidin (NCTD) with paclitaxel on DU145 prostate cancer (PCa) cells. The median effective dose for $50 \%$ of the cell population $\left(\mathrm{ED}_{50}\right)$ values of NCTD, paclitaxel or a combination of both were determined by MTT assay. The combination index (CI) value of the combination treatment with NCTD $(\mu \mathrm{M})$ and paclitaxel (nM) with a constant ratio of 1:1 were calculated using Calcusyn1 software. Each experiment was independently carried out 3 times. Data represent the means \pm SD.

\section{Discussion}

As is well known, cancer cells have an infinite proliferation ability. The ability of DNA replication in cancer cells is promoted in order to achieve cell division. The assembly of pre-RCs on chromatin is indispensable to initiate DNA replication (12). Cdc6 plays an important role in the formation and maintainence of pre-RCs (12). In our study, NCTD was verified to have the ability of inhibiting $\mathrm{PCa}$ cell growth with an $\mathrm{IC}_{50}$ of approximately $200 \mu \mathrm{M}$ (Fig. 1). The BrdU labeling assay demonstrated that NCTD effectively inhibited DNA replication in cultured DU145 cells (Fig. 2). The initiation proteins, Cdc6 and Mcm6, were degraded (Fig. 3), and were prevented from binding to chromatin following treatment with NCTD (Fig. 4). These results demonstrate that NCTD suppresses DNA replication by the degradation of Cdc6 and Mcm6 and as a result, blocks the formation of pre-RCs.

Cell cycle dysregulation is a hallmark of tumor cells. The regulation of proteins that mediate critical events in the cell cycle can be a useful method for the treatment of tumors (31). In our study, a larger proportion of PCa cells with aberrant mitosis following treatment with NCTD was observed (Fig. 7). Previous studies have indicated that human Cdc6 physically interacts 
with ATR in a Cdk-phosphorylation-stimulated manner and that Cdc6 is required for the ATR-dependent replication-checkpoint response activated by modest replication stress (15). In this study, we found that the chromatin binding fraction of ATR emerged and was reduced following treatment with NCTD in a dose-dependent manner (Fig. 5). The blocking of ATR binding to chromatin leads to premature mitosis before replication has been completed; mitotic catastrophe is lethal to cells (28). In this study, we compared the cell cycle distribution of HU-treated and HU/NCTD-treated DU145 cells and found that a large proportion of cells progressed to the G2/M phase; we also observed cells in the sub-G1 phase in the HU/NCTD-treated group. The HU-treated cells were blocked in the $\mathrm{S}$ phase and were prevented from entering the $\mathrm{G} 2 / \mathrm{M}$ phase in the presence of the activation of the checkpoint pathway (Fig. 6). Cell cycle analysis revealed that NCTD induced mitotic catastrophe, possibly by disturbing the interaction of Cdc6 and ATR. However, the exact correlation between Cdc6, ATR and mitotic catastrophe requires further investigation. Therefore, NCTD kills DU145 cells not only by suppressing DNA replication in the G1 phase but also by inducing mitotic catastrophe during the $\mathrm{S} / \mathrm{G} 2 \mathrm{M}$ transition.

In this study, we investigated the synergistic anti-neoplastic effect of paclitaxel combined with NCTD in DU145 PCa cells. Our results revealed that the combination of NCTD and paclitaxel was highly synergistic at low concentrations (Fig. 8). Firstly, NCTD can induce apoptosis through multiple pathways, including inhibiting the initiation of DNA replication $(32,33)$. Secondly, NCTD can inhibit the assembly of Cdc6 and ATR on chromatin, which is essential in the ATR-dependent checkpoint pathway. The blocking of the activation of the ATR-dependent checkpoint pathway results in premature entry into mitosis before the completion of DNA replication and mitotic catastrophe, a lethal event for cells (28). When the ATR-dependent checkpoint pathway is obstructed, more cells, which should have been blocked in the S phase, will abnormally enter into mitosis. Therefore, a larger proportion of vulnerable cells in aberrant mitosis may favorably contribute to the anticancer effects of paclitaxel. A lower dose of the combination of the 2 drugs may achieve a stronger effect with fewer side-effects. Unlike the majority of anticancer drugs, NCTD has significant advantages of inducing myelosuppression and inducing leucocytosis, making it a promising candidate for use in combination treatments.

In conclusion, NCTD exerts anticancer effects by inhibiting the formation and maintenance of pre-RCs, and inducing mitotic catastrophe in DU145 cells. Its multistage and multipath antitumor effects make it a promising candidate for use in combination treatments. In addition, $\mathrm{Cdc} 6$ may be a promising anticancer target in PCa.

\section{Acknowledgements}

This study was supported by grants from the National Natural Science Foundation of China (nos. 30901822, 81272482 and 81072113)

\section{References}

1. Greenlee RT, Murray T, Bolden S and Wingo PA: Cancer statistics. CA Cancer J Clin 50: 7-33, 2000.
2. Quinn $\mathrm{M}$ and Babb P: Patterns and trends in prostate cancer incidence, survival, prevalence and mortality. Part I: international comparisons. BJU Int 90: 162-173, 2002.

3. Cude KJ, Dixon SC, Guo Y, Lisella J and Figg WD: The androgen receptor: genetic considerations in the development and treatment of prostate cancer. J Mol Med (Berl) 77: 419-426, 1999.

4. Robles LD, Frost AR, Davila M, Hutson AD, Grizzle WE and Chakrabarti R: Down-regulation of Cdc6, a cell cycle regulatory gene, in prostate cancer. J Biol Chem 277: 25431-25438, 2002.

5. Mallik I, Davila M, Tapia T, Schanen B and Chakrabarti R: Androgen regulates Cdc6 transcription through interactions between androgen receptor and E2F transcription factor in prostate cancer cells. Biochim Biophys Acta 1783: 1737-1744, 2008.

6. Claessens F, Verrijdt G, Schoenmakers E, et al: Selective DNA binding by the androgen receptor as a mechanism for hormone-specific gene regulation. J Steroid Biochem Mol Biol 76: 23-30, 2001

7. Wang Q, Li W, Liu XS, et al: A hierarchical network of transcription factors governs androgen receptor-dependent prostate cancer growth. Mol Cell 27: 380-392, 2007.

8. Bolton EC, So AY, Chaivorapol C, Haqq CM, Li H and Yamamoto KR: Cell- and gene-specific regulation of primary target genes by the androgen receptor. Genes Dev 21: 2005-2017, 2007.

9. Massie CE, Adryan B, Barbosa-Morais NL, et al: New androgen receptor genomic targets show an interaction with the ETS1 transcription factor. EMBO Rep 8: 871-878, 2007.

10. Jin F and Fondell JD: A novel androgen receptor-binding element modulates Cdc6 transcription in prostate cancer cells during cell-cycle progression. Nucleic Acids Res 37: 4826-4838, 2009.

11. Cook JG: Replication licensing and the DNA damage checkpoint. Front Biosci 14: 5013-5030, 2009.

12. Stillman B: Cell cycle control of DNA replication. Science 274: 1659-1664, 1996

13. Saxena S and Dutta A: Geminin-Cdt1 balance is critical for genetic stability. Mutat Res 569: 111-121, 2005.

14. Lei M and Tye BK: Initiating DNA synthesis: from recruiting to activating the MCM complex. J Cell Sci 114: 1447-1454, 2001.

15. Yoshida K, Sugimoto N, Iwahori S, et al: CDC6 interaction with ATR regulates activation of a replication checkpoint in higher eukaryotic cells. J Cell Sci 123: 225-235, 2010.

16. Wang GS: Medical uses of Mylabris in ancient China and recent studies. J Ethnopharmacol 26: 147-162, 1989.

17. Chang $\mathrm{C}$, Zhu Y, Tang $\mathrm{X}$ and Tao W: The anti-proliferative effects of norcantharidin on human HepG2 cells in cell culture. Mol Biol Rep 38: 163-169, 2011.

18. Luan J, Duan H, Liu Q, Yagasaki K and Zhang G: Inhibitory effects of norcantharidin against human lung cancer cell growth and migration. Cytotechnology 62: 349-355, 2010.

19. Chen YJ, Chang WM, Liu YW, et al: A small-molecule metastasis inhibitor, norcantharidin, downregulates matrix metalloproteinase-9 expression by inhibiting Sp1 transcriptional activity in colorectal cancer cells. Chem Biol Interact 181: 440-446, 2009

20. Huang Y, Liu Q, Liu K, Yagasaki K and Zhang G: Suppression of growth of highly-metastatic human breast cancer cells by norcantharidin and its mechanisms of action. Cytotechnology 59: 209, 2009.

21. Kok SH, Cheng SJ, Hong CY, et al: Norcantharidin-induced apoptosis in oral cancer cells is associated with an increase of proapoptotic to antiapoptotic protein ratio. Cancer Lett 217: 43-52, 2005.

22. Liu XH, Blazsek I, Comisso M, et al: Effects of norcantharidin, a protein phosphatase type-2A inhibitor, on the growth of normal and malignant haemopoietic cells. Eur J Cancer 31A: 953-963, 1995.

23. Ofir Y, Sagee S, Guttmann-Raviv N, Pnueli L and Kassir Y: The role and regulation of the preRC component Cdc6 in the initiation of premeiotic DNA replication. Mol Biol Cell 15: 2230-2242, 2004.

24. Forsburg SL: Eukaryotic MCM proteins: beyond replication initiation. Microbiol Mol Biol Rev 68: 109-131, 2004.

25. Lau E, Zhu C, Abraham RT and Jiang W: The functional role of Cdc6 in S-G2/M in mammalian cells. EMBO Rep 7: 425-430, 2006.

26. Liu Q, Guntuku S, Cui XS, et al: Chk1 is an essential kinase that is regulated by Atr and required for the G(2)/M DNA damage checkpoint. Genes Dev 14: 1448-1459, 2000. 
27. Clay-Farrace L, Pelizon C, Santamaria D, Pines J and Laskey RA Human replication protein Cdc6 prevents mitosis through a checkpoint mechanism that implicates Chk1. EMBO J 22: 704-712, 2003.

28. Vakifahmetoglu H, Olsson M and Zhivotovsky B: Death through a tragedy: mitotic catastrophe. Cell Death Differ 15: 1153-1162, 2008.

29. McGuire WP, Rowinsky EK, Rosenshein NB, et al: Taxol: a unique antineoplastic agent with significant activity in advanced ovarian epithelial neoplasms. Ann Intern Med 111: 273-279, 1989.

30. Horwitz SB: Taxol (paclitaxel): mechanisms of action. Ann Oncol 5 (Suppl 6): S3-S6, 1994.
31. Stewart ZA, Westfall MD and Pietenpol JA: Cell-cycle dysregulation and anticancer therapy. Trends Pharmacol Sci 24: 139-145, 2003.

32. Chen YN, Chen JC, Yin SC, et al: Effector mechanisms of norcantharidin-induced mitotic arrest and apoptosis in human hepatoma cells. Int J Cancer 100: 158-165, 2002.

33. Chen YN, Cheng CC, Chen JC, Tsauer W and Hsu SL: Norcantharidin-induced apoptosis is via the extracellular signal-regulated kinase and c-Jun-NH2-terminal kinase signaling pathways in human hepatoma HepG2 cells. Br J Pharmacol 140: 461-470, 2003. 